\title{
MENGEMBANGKAN SOFT SKILLS GURU UNTUK MENDIDIK AKHLAK MULIA SISWA
}

\author{
Ach. Saifullah \\ Institut Agama Islam Bani Fattah Jombang \\ achsaifullah@iaibafa.ac.id
}

\begin{abstract}
Soft Skills are the non-technical abilities that a person possesses when dealing with himself (intra-personal skills) and others (inter-personal skills). While morals are the nature of deeds that have been embedded and rooted very strongly in a person so that to do it will be easy and easy without any thoughts and considerations. The role and duties of teachers are not limited to transferring knowledge. Personality competence and social competence are needed as soft competences to educate students' morals. This shows that the soft skills of a teacher become software that always accompanies the learning process.
\end{abstract}

Keywords: soft skills, teacher, students' morals

\section{PENDAHULUAN}

Fenomena melorotnya akhlak generasi bangsa kerap menjadi sorotan miring dan kritikan pedas terhadap institusi pendidikan. Hal tersebut dirasa wajar mengingat pendidikan nasional mengemban misi yang amat mendasar yakni membentuk manusia utuh dengan akhlak mulia sebagai salah satu indikator utama. Undang-Undang No. 20 tahun 2003 Bab II pasal 3 memuat fungsi dan tujuan pendidikan nasional bahwa pendidikan nasional berfungsi mengembangkan kemampuan dan membentuk watak serta peradaban bangsa yang bermartabat dalam rangka mencerdaskan kehidupan bangsa, bertujuan untuk berkembangnya potensi peserta didik agar menjadi manusia yang beriman dan bertakwa kepada Tuhan Yang Maha Esa, berakhlak mulia, 
sehat, berilmu, cakap, kreatif, mandiri, dan menjadi warga negara yang demokratis serta bertanggung jawab. ${ }^{1}$

Tertulisnya kata-kata berakhlak mulia dalam tujuan pendidikan nasional mengisyaratkan bangsa Indonesia menetapkan cita-cita akhlak mulia sebagai karakter dalam kehidupan berbangsa dan bernegara. Apalagi umat muslim sebagai umat mayoritas akan menjadi daya dukung tersendiri bagi terwujudnya kehidupan masyarakat yang dilandasi nilainilai akhlak mulia.

Faktanya ada distorsi antara yang dicita-citakan dengan realitas praktek pendidikan. Pendidikan di Indonesia cenderung berorientasi pada pendidikan berbasis hard skill (keterampilan teknis) yang lebih banyak bertumpu pada intelligence quotient (IQ), namun kurang mengembangkan kemampuan soft skill yang mengembangkan kemampuan emotional intelligence (EQ) dan spiritual intelligence (SQ).

Potensi kecerdasan diri yang harus dikembangkan secara aktif oleh peserta didik dengan bimbingan para pendidik tidak hanya terkonsentrasi pada kecerdasan intelektual akademis tetapi juga kecerdasan karakter (soft skill) yang justru sangat diperlukan untuk kesuksesan karier peserta didik dalam masyarakatnya. ${ }^{2}$

Sebagai bagian penting dari komponen pelaksanaan pembelajaran, guru memiliki andil yang cukup signifikan dalam menentukan gagal atau suksesnya penanaman nilai-nilai akhlak. Selain upaya mengoptimalkan kecerdasan intelektual siswa, guru juga dituntut untuk menanamkan nilainilai budi pekerti, moral, dan akhlak mulia yang kini dikenal dengan pendidikan karakter. Peranan guru dalam membantu proses internalisasi nilai-nilai positif ke dalam diri siswa tidak bisa digantikan oleh media pendidikan secanggih apapun. Hal ini karena pendidikan karakter membutuhkan teladan hidup (living model) yang hanya bisa ditemukan dalam pribadi para guru. Tanpa peranan guru, pendidikan karakter tidak akan pernah berhasil dengan baik. ${ }^{3}$

${ }^{1}$ Prof. Dr. H. Sofyan Sauri, M.Pd, Strategi Meningkatkan Pendidikan Akblak Peserta Didike
$\begin{aligned} & \text { Dalam Pembelajaran, Available } \\ & \text { Proses }\end{aligned}$ $\begin{array}{lll}\text { Dalam } & \text { Proses } & \text { Pembelajaran, Available at: } \\ \text { http://file.upi.edu/Direktori/FPBS/JUR._PEND._BAHASA_ARAB/1956042019830 }\end{array}$ 11-SOFYAN_SAURI/makalah2/STRATEGI_MENINGKATKAN_AKHLAK.pdf. Diakses tanggal 4 November 2011.

2 Prof. Mohammad Adnan Latief, M.A., Ph.D, Pengembangan Soft Skills Melalui Pembelajaran Bahasa Inggris Berbasis Konteks, Pidato Pengukuhan Guru Besar Dalam Bidang Ilmu Pendidikan Bahasa Inggris Pada Fakultas Sastra Disampaikan pada Sidang Terbuka Senat Universitas Negeri Malang, Departemen Pendidikan Nasional Universitas Negeri Malang, 2007.

${ }^{3}$ Dr. Abdul Abdul Munip, M.Ag, Reinveting Nilai-Nilai Islam Mengenai Peranan Guru Dalam Pendidikan Karakter, Available at: http://www.scribd.com/doc/12991475/GuruDalam-Pendidikan-Karakter. Diakses 4 November 2011. 
Demi tercapainya internalisasi nilai-nilai akhlak ke dalam diri siswa, kesadaran bahwa guru sebagai pribadi yang menjadi teladan hidup tidak bisa diabaikan. Inilah kompetensi kepribadian yang harus dimiliki guru, selain tiga kompetensi lainnya, yakni kompetensi profesional, kompetensi pedagogik, dan kompetensi sosial. Keempat kompetensi tersebut saling terkait dan harus dimiliki guru.

Dalam modul Materi Peningkatan Kompetensi Guru Pendidikan Agama Islam dijelaskan bahwa keempat kompetensi tersebut dapat dikelompokkan menjadi dua, yaitu hard competence dan soft competence. Yang termasuk hard competence adalah kompetensi profesional dan kompetensi pedagogik. Sementara yang termasuk soft competence adalah kompetensi kepribadian dan kompetensi sosial. ${ }^{4}$

Kompetensi kepribadian dan kompetensi sosial seorang guru sebagai soft competence akan sangat berpengaruh pada soft competence siswa yang dalam hal ini salah satunya akan ditunjukkan oleh sikap dan berbudi pekerti siswa. Guru bukan hanya harus terampil mengajar (bard competence), tetapi juga musti piawai mendidik (soft competence). Dalam mengajar guru bertugas mentransfer pengetahuan (transfer of knowledge), sedangkan dalam mendidik guru bertanggung jawab mentransfer nilai (transfer of value).

Oleh karena itu, soft skills guru memberikan kontribusi yang cukup signifikan dalam membentuk kepribadian siswa yang menjadikan akhlak mulia sebagai rujukan nilai dalam berperilaku. Degradasi moral siswa dapat diatasi salah satunya dengan meningkatkan kualitas soft skill guru.

\section{PENGERTIAN SOFT SKILLS}

Tidak ada kesepakatan tunggal tentang makna soft skills, tetapi secara umum istilah ini digunakan untuk mendeskripsikan kemampuan berkembang dalam pekerjaan. Sebagai contoh kemampuan seorang arsitek untuk membaca dan menerjemahkan gambar perencanaan merupakan hard skills, namun kemampuan untuk bekerja efektif dengan bawahannya, komunikasi dengan pelanggan dan atasan merupakan aspek soft skills. Dalam hal ini soft skills diistilahkan pula dengan employability skills. ${ }^{5}$

Definisi soft skills menurut wikipedia (wikipedia.com) adalah:

\footnotetext{
${ }^{4}$ Ali Mudlofir (2011), Modul Pengembangan Soft Skills Guru PAI, Materi Peningkatan Guru Pendidikan Agama Islam, Direktorat Pendidikan Agama Islam, Kementerian Agama Republik Indonesia, hlm. 8.

5 William P. Breitsprecher, 2006, Employability Skills. Available at: http://www.breitlinks.com/careers/soft skills.htm. Diakses tanggal 4 November 2011.
} 
Soft skills is a sociological term relating to a person's "EQ" (Emotional Intelligence Quotient), the cluster of personality traits, social graces, communication, language, personal habits, friendliness, and optimism that characterize relationships with other people. Soft skills complement hard skills (part of a person's IQ), which are the occupational requirements of a job and many other activities. ${ }^{6}$

Menurut Prof. Dr. I Wayan Simri Wicaksana, S.Si., M.Eng, soft skills adalah sebuah istilah dalam sosiologi tentang EQ (Emotional Intelligence Quotient) seseorang yang dapat dikategorikan / diklusterkan menjadi kehidupan sosial, komunikasi, bertutur bahasa, kebiasaan, keramahan, optmasi. ${ }^{7}$

Soft skills adalah istilah sosiologis yang berkaitan dengan kecerdasan emosional, sifat kepribadian, keterampilan sosial, komunikasi, berbahasa, kebiasaan pribadi, keramahan, dan optimisme yang mencirikan kemampuan seseorang dalam berhubungan dengan orang lain. Soft skills merupakan kecerdasan emosional dan sosial (Emotional Inteligence Quotient) yang sangat penting untuk melengkapi hard skills atau kecerdasan intelektual (Intelligence Quotient). ${ }^{8}$

Soft skills merupakan kompetensi perilaku seseorang (people skills) yang berkaitan dengan bagaimana dia memperlakukan dirinya dan orang lain. Soft skills juga dipahami sebagai sekumpulan keterampilan generik yang mencakup unsur-unsur kognitif yang terkait dengan keterampilan non-akademik.

Dalam situs School of Educator, Vishal Jain dalam tulisan berjudul Importance of Soft Skills Development in Education menulis:

Soft skills are identified to be the most critical skills in the current global job market especially in a fast moved era of technology. The reorientation of education which is one trust of education for sustainability also relates the importance of these socalled soft skills. ${ }^{9}$

Paparan di atas menjelaskan identifikasi soft skills beserta urgensinya di era pasar kerja global saat ini. Keterampilan yang terkandung dalam soft skills oleh Jain dikategorikan dalam dua kelompok,

\footnotetext{
${ }^{6}$ Wikipedia, Soft Skills, Available at: http://en.wikipedia.org/wiki/Soft skills. Diakses tanggal 4 November 2011.

${ }^{7}$ Prof. Dr. I Wayan Simri Wicaksana, S.Si., M.Eng, Soft Skills, Gunadarma Univesity. Available at: http://iwayan.info/Lecture/Softskills/MateriKelasSoftSkill ver100214 IWS.pdf. Diakses tanggal 13 Pebruari 2013.

8 Sri Yuliani, Apa Itu Soft Skills. Available at: http://sriyuliani.staff.fisip.uns.ac.id/kuliah/apa-itu-soft-skills. Diakses tanggal 13 Pebruari 2013.

9 Vishal Jain, Importance of Soft Skills Development in Education. Available at: http://schoolofeducators.com/2009/02/importance-of-soft-skills-development-ineducation. Diakses tanggal 13 Pebruari 2013.
} 
yaitu keterampilan yang harus dimiliki (must have) dan keterampilan yang bagus untuk dimiliki (good to have). Berikut tabel kategorisasi soft skills menurut Jain. ${ }^{10}$

tabel 2.1

the "must have" and "good to have"

elements of soft skills

\begin{tabular}{|c|c|c|c|}
\hline No & Soft Skills & $\begin{array}{l}\text { Must Have Elements } \\
\text { (Sub-Skills) }\end{array}$ & $\begin{array}{l}\text { Good To Have } \\
\text { Elements (Sub- } \\
\text { Skills) }\end{array}$ \\
\hline 1. & $\begin{array}{l}\text { Communicative } \\
\text { Skills }\end{array}$ & $\begin{array}{l}\text { Ability to deliver idea } \\
\text { clearly, effectively and } \\
\text { with confidence either } \\
\text { orally or in writing } \\
\text { Ability to practice } \\
\text { active listening skill and } \\
\text { respond. } \\
\text { Ability to present } \\
\text { clearly and confidently } \\
\text { to the audience. }\end{array}$ & $\begin{array}{l}\text { Ability to use } \\
\text { technology during } \\
\text { presentation. } \\
\text { Ability to discuss } \\
\text { and arrive at a } \\
\text { consensus. } \\
\text { Ability to } \\
\text { communicate with } \\
\text { individual from a } \\
\text { different cultural } \\
\text { background. } \\
\text { Ability to expand } \\
\text { one's own } \\
\text { communicative skill. } \\
\text { Ability to use non- } \\
\text { oral skills. }\end{array}$ \\
\hline 2. & $\begin{array}{l}\text { Critical Thinking } \\
\text { and Problem } \\
\text { Solving Skills }\end{array}$ & $\begin{array}{l}\text { Ability to identify and } \\
\text { analyze problems in } \\
\text { difficult situation and } \\
\text { make justifiable } \\
\text { evaluation. } \\
\text { Ability to expand and } \\
\text { improve thinking skills } \\
\text { such as explanation, } \\
\text { analysis and evaluate } \\
\text { discussion. } \\
\text { Ability to find ideas } \\
\text { and look for alternative } \\
\text { solutions. } \\
\end{array}$ & $\begin{array}{l}\text { Ability to think } \\
\text { beyond.. } \\
\text { Ability to make } \\
\text { conclusion based on } \\
\text { valid proof. } \\
\text { Ability to withstand } \\
\text { and give full } \\
\text { responsibility. } \\
\text { Ability to understand } \\
\text { and accommodate } \\
\text { oneself to the varied } \\
\text { working environment. }\end{array}$ \\
\hline 3. & Team Work & Ability to build a & Ability to give \\
\hline
\end{tabular}

10 Ibid. 


\begin{tabular}{|c|c|c|c|}
\hline & & $\begin{array}{l}\text { good rapport, interact } \\
\text { and work effectively } \\
\text { with others. } \\
\text { Ability to understand } \\
\text { and play the role of a } \\
\text { leader and follower } \\
\text { alternatively. } \\
\text { Ability to recognize } \\
\text { and respect other's } \\
\text { attitude, behavior and } \\
\text { beliefs. }\end{array}$ & $\begin{array}{l}\text { contribution to the } \\
\text { planning and } \\
\text { coordinate group } \\
\text { work. } \\
\text { Responsible towards } \\
\text { group decision. }\end{array}$ \\
\hline 4. & $\begin{array}{l}\text { Life-Long } \\
\text { Learning \& } \\
\text { Information } \\
\text { Management Skill }\end{array}$ & $\begin{array}{l}\text { Ability to find and } \\
\text { manage relevant } \\
\text { information from } \\
\text { various sources. } \\
\text { Ability to receive new } \\
\text { ideas performs } \\
\text { autonomy learning. }\end{array}$ & $\begin{array}{l}\text { Ability to develop an } \\
\text { inquiry mind and seek } \\
\text { knowledge. }\end{array}$ \\
\hline 5. & $\begin{array}{l}\text { Entrepreneurshi } \\
\text { p skill }\end{array}$ & $\begin{array}{l}\text { Ability to identify job } \\
\text { opportunities. }\end{array}$ & $\begin{array}{l}\text { Ability to propose } \\
\text { business opportunity. } \\
\text { Ability to build, } \\
\text { explore and seek } \\
\text { business opportunities } \\
\text { and job. } \\
\text { Ability to be self- } \\
\text { employed. }\end{array}$ \\
\hline 6. & $\begin{array}{l}\text { Ethics, Moral \& } \\
\text { Professional }\end{array}$ & $\begin{array}{l}\text { Ability to understand } \\
\text { the economy crisis, } \\
\text { environment and social } \\
\text { cultural aspects } \\
\text { professionally. } \\
\text { Ability to analyze } \\
\text { make problem solving } \\
\text { decisions related to } \\
\text { ethics. }\end{array}$ & $\begin{array}{l}\text { Ability to practice } \\
\text { ethical attitudes } \\
\text { besides having the } \\
\text { responsibility towards } \\
\text { society. }\end{array}$ \\
\hline 7. & Leadership skill & $\begin{array}{l}\text { Knowledge of the } \\
\text { basic theories of } \\
\text { leadership. } \\
\text { Ability to lead a } \\
\text { project. }\end{array}$ & $\begin{array}{l}\text { Ability to understand } \\
\text { and take turns as a } \\
\text { leader and follower } \\
\text { alternatively. } \\
\text { Ability to supervise } \\
\text { members of a group. }\end{array}$ \\
\hline
\end{tabular}


Dalam buku "Pengembangan Soft Skills dalam Proses Pembelajaran di Perguruan Tinggi" mengutip pendapat Illah Sailah dalam buku "Pengembangan Soft Skills di Perguruan Tinggi" menyatakan definisi soft skills sebagai:

- Keterampilan seseorang dalam berhubungan dengan orang lain (inter-personal skills) dan keterampilan dalam mengatur dirinya sendiri (intra-personal skills) yang mampu mengembangkan secara maksimal unjuk kerja (performans) seseorang.

- Selanjutnya diberikan contoh-contoh yang termasuk dalam keterampilan mengatur dirinya sendiri antara lain (a) transforming character, (b) transforming beliefs, (c) change management, (d) stress management, (e) time management, (f) creative thinking processes, (h) goal setting and life purpose, (i) acelerated learning techniques, dan lain-lain.

- Sedangkan contoh keterampilan dalam berhubungan dengan orang lain di antaranya adalah (a) communication skill, (b) relationship building, (c) motivation skills, (d) leadership skills, (e) self-marketing skills, (f) negotiatian skills, (g) presentation skills, (h) public speaking skills, dan lain lain. ${ }^{11}$

Dari uraian definisi di atas dapat dirumuskan bahwa soft skills merupakan kemampuan non-teknis yang diperlukan saat berhubungan dengan diri sendiri (intra-personal skills) dan orang lain (inter-personal skills) guna mengembangkan kemampuan seseorang. Soft skills merupakan komplemen hard skills yang akan menentukan kesuksesan seseorang dalam bekerja.

\section{DIMENSI SOFT SKILLS}

Menurut Illah Sailah dimensi soft skills dipetakan menjadi dua bagian, yakni:

a.Keterampilan mengatur dirinya sendiri yang meliputi: (1) transforming character, (2) transforming beliefs, (3) change management, (4) stress management, (5) time management, (6) creative thinking processes, (7) goal setting and life purpose, (8) acelerated learning techniques, dan lain-lain.

b. Keterampilan berhubungan dengan orang lain yang meliputi: (1) communication skill, (2) relationship building, (3) motivation skills, (4) leadership skills, (5) self-marketing skills, (6) negotiatian skills, (7) presentation skills, (8) public speaking skills, dan lain lain. ${ }^{12}$

\footnotetext{
11 Pengembangan Soft Skills dalam Proses Pembelajaran di Perguruan Tinggi (2008), Makna Soft Skills, Direktorat Akademik Direktorat Jenderal Pendidikan Tinggi Departemen Pendidikan Nasional, Jakarta, hlm. 4.

${ }^{12}$ Ibid.
} 
Dalam pandangannya tentang kecerdasan emosional Daniel Goleman menyatakan, agar mempunyai kecerdasan emosional secara garis besar ada lima tahapan kesadaran dan keterampilan diri, yaitu kesadaran diri (self-awareness), pengaturan diri (self- social skill), motivasi (motivation), empati (empathy), dan keterampilan sosial (social skill). Tiga yang pertama, yakni kesadaran diri, pengaturan diri, dan motivasi lebih terkait dengan kecerdasan intrapersonal. Sedangkan dua yang terakhir, yakni empati dan keterampilan sosial lebih terkait dengan kecerdasan interpersonal. ${ }^{13}$

Dari pandangan di atas dapat dikemukakan bahwa soft skill memiliki dua dimensi yang terkait dengan kecerdasan seseorang, yaitu keterampilan mengatur dirinya sendiri (intra-personal skills) dan keterampilan berhubungan dengan orang lain (interpersonal skills).

Intra-personal skills meliputi:

a. Keterampilan manajemen waktu.

Keterampilan seseorang dalam membuat perencanaan waktu berdasarkan kepentingan dan prioritas. ${ }^{14}$

b. Keterampilan manajemen stres.

Keterampilan ini berkaitan dengan bagaimana seseorang mengelola stres. ${ }^{15}$ Susatyo Yuwono dalam tulisan berjudul Mengelola Stres dalam Perspektif Islam dan Psikologi mengutip pendapat Athar menyatakan bahwa cara mengelola stres yang diajarkan Islam di antaranya adalah niat ikhlas (QS. At-Taubah: 91), sabar dan shalat (QS. Al-Baqarah: 153), bersyukur dan bertawakkal (QS. Al-Baqarah: 156), doa dan dzikir (QS. Ar-Ra'd: 28). ${ }^{16}$

c. Keterampilan keyakinan diri.

\footnotetext{
13 Ali Mudlofir (2011) Modul Pengembangan Soft Skills Guru PAI, Materi Peningkatan Guru Pendidikan Agama Islam. Direktorat Pendidikan Agama Islam, Kementerian Agama Republik Indonesia, Jakarta. Hal. 9

${ }^{14}$ Lihat Seri Peningkatan Kualitas Pembelajaran TIUI, Keterampilan Mengatur Waktu, Departemen Teknik Industri Universitas Jakarta. Availble at: http://staff.ui.ac.id/internal/132161161/material/Seri4-

KeterampilanMengelolaWaktu.pdf. Diakses tanggal 13 Pebruari 2013.

${ }^{15}$ Dalam ilmu psikologi stres merupakan respon individu terhadap situasi dan peristiwa yang dianggap mengancam (JW Santrock: 2000). Menurut Magill (1996) stres merupakan reaksi adaptif individu terhadap situasi yang dipersepsikan sebagai ancaman. Dalam Islam stres merupakan ujian atau cobaan dari Allah Swt. "Dan sunggub akan Kami berikan cobaan kepadamu, dengan sedikit ketakutan, kelaparan, kekurangan barta, jiwa dan buahbuahan. Dan berikanlah berita gembira kepada orang-orang yang sabar.” (QS. Al-Baqarah [2]: 155.

${ }^{16}$ Susatyo Yuwono, Mengelola Stres dalam Perspektif Islam dan Psikologi. Available at: jurnal.ump.ac.id/index.php/psikologi/article/download/249/235. Diakses tanggal 14 Pebruari 2013.
} 
Konsep keyakinan diri pertama kali dikemukakan oleh Bandura. Keyakinan diri mengacu pada persepsi tentang kemampuan individu untuk mengorganisasi dan mengimplementasi tindakan untuk menampilkan kecakapan tertentu. ${ }^{17}$ Keyakinan diri merupakan perasaan individu mengenai kemampuan dirinya untuk membentuk perilaku yang relevan dalam situasi-situasi khusus yang mungkin tidak dapat diramalkan dan mungkin menimbulkan stres.

d. Keterampilan karakter diri.

Dalam Kamus Besar Bahasa Indonesia, karakter diartikan sebagai sifat-sifat kejiwaan, akhlak atau budi yang menjadi ciri khas seseorang. ${ }^{18}$ Karakter merupakan sebuah sistem keyakinan dan kebiasaan yang mengarahkan tindakan seorang individu. Karena itu, jika pengetahuan mengenai karakter seseorang itu dapat diketahui, maka dapat diketahui pula bagaimana individu tersebut akan bersikap untuk kondisi-kondisi tertentu. ${ }^{19}$

e.Keterampilan berpikir kreatif.

Creativity is the impetus behind any given act of creation: inventions, compositions, etc. It is a fundamental human compulsion and largely related to notions of what separates human from machine intelligence. ${ }^{20} \mathrm{Ada}$ empat pilar creative thinking skills, yaitu associating, questioning, observing, dan experimenting. ${ }^{21}$

f. Keterampilan tujuan hidup.

Syekh Tosun Bayrak dan Murtadha Muthahari mengutip pandangan Ibnu Sina dalam Futuhaat al-Makiyyah menyatakan bahwa Allah menciptakan manusia agar diri-Nya dikenal. ${ }^{22}$ Maka, tujuan hidup seseorang sesungguhnya adalah mengenal Allah Swt dengan cara menghamba kepada-Nya.

g. Keterampilan teknik percepatan belajar.

17 Bandura A. 1986. Social Foundation of Thought and Action: A Social CognitiveTheory. Englewood Cliffs, New York:Prentice Hall, hal. 361. Available at: http://eprints.undip.ac.id/10382/1/Novikarisma Wijaya.pdf. Diakses tanggal 14 Pebruari 2013.

${ }^{18}$ Em Zul Fajri dan Ratu Aprilia Senja (2003), Kamus Lengkap Bahasa Indonesia, Dhifa Publiser, Jakarta, hal. 422.

${ }^{19}$ Mengenal Hakekat Karakter. Available at: http://charachterbuilding.wordpress.com. Diakses tanggal 14 Pebruari 2013.

${ }^{20}$ Wikipedia, Creativity, Available at: http://en.wikipedia.org/wiki/Creativity. Diakses tanggal 14 Pebruari 2013.

21 Yodhia Antariksa, 4 Pilar Creative Thingking Skills. Available at: http://strategimanajemen.net/2009/12/21/4-pilar-creative-thinking-skills. Diakses tanggal 14 Pebruari 2013.

${ }_{22}$ Murtadha Muthahhari dan Syekh Tosun Bayrak (2007), Energi Ibadab: Selami Makna, Raih Kematangan Batin, Serambi, Jakarta, hal. 217. 
Dalam situs The Center for Accelerated Learning dinyatakan bahwa:

Accelerated learning (A.L.) is the most advanced teaching and learning method in use today. It's a total system for speeding and enhancing both the design process and the learning processes. Based on the latest brain research, it has proven again and again to increase learning effectiveness while saving time and money in the process. $^{23}$

Teknik accelerated learning yang berbasis pada efektivitas dan optimalisasi kerja otak menjadikan seseorang hemat waktu, biaya, dan bisa mencapai percepatan hasil belajar yang optimal.

Interpersonal skills didefinisikan sebagai keterampilan untuk mengenali dan merespons secara layak perasaan, sikap dan perilaku, motivasi serta keinginan orang lain. Bagaimana diri kita mampu membangun hubungan yang harmonis dengan memahami dan merespons manusia atau orang lain merupakan bagian dari keterampilan interpersonal. ${ }^{24}$ Interpersonal skills meliputi: keterampilan memotivasi, keterampilan memimpin, keterampilan presentasi, keterampilan berkomunikasi, keterampilan membangun hubungan.

\section{URGENSI SOFT SKILLS BAGI GURU}

Jika dikaitkan dengan hasil penelitian di berbagai perusahaan besar tentang keberhasilan seorang profesional, penguasaan soft skills lebih dibutuhkan daripada hard skills. Menurut buku Lesson From The Top, karya Neff dan Citrin (1990), yang memuat sharing dan wawancara 50 orang tersukses di Amerika, mereka sepakat bahwa yang paling menentukan kesuksesan bukanlah keterampilan teknis, melainkan kualitas diri yang termasuk di dalamnya adalah keterampilan lunak (soft skills) atau keterampilan berhubungan dengan orang lain (people skills). ${ }^{25}$ Penelitian ini menguatkan bahwa kesuksesan seseorang ditentukan oleh sekitar 80\% soft skills dan sisanya $20 \%$ hard skills.

Sebagai profesi yang diakui guru juga dituntut memiliki keterampilan hard skill dan soft skill. Dua keterampilan ini perlu dikembangkan secara seimbang. Guru dituntut bukan hanya terampil membuat lesson plan, menyusun materi ajar, memilih media pembelajaran, mengevaluasi hasil kerja siswa, yang semua itu termasuk kategori

23 The Center for Accelerated Learning, What is Accelerated learning. Available at: bttp:// www.alcenter.com/what is.php. Diakses tanggal 14 Pebruari 2013.

${ }^{24}$ Diklat Penjenjangan Auditor Pengendali Teknis (2007), Interpersonal Skill, Pusat Pendidikan dan Pelatihan Pengawasan Badan Pengawasan Keuangan dan Pembangunan, BPKP, Jakarta, hal.2.

${ }_{25}$ Ali Mudlofir, Op. Cit., hlm. 8 
keterampilan teknis (bard skills), tetapi lebih dari itu: guru juga harus memiliki keunggulan kualitas diri yang bersifat ke dalam dan keluar (soft skills).

Merujuk pada buku Lesson From The Top, keterampilan soft skills sangat dibutuhkan oleh guru. Kesuksesan seorang guru yang ditopang oleh keterampilan soft skills yang tinggi bukan hanya berpengaruh pada karier pribadi semata, bahkan akan sangat berpengaruh pada kesuksesan siswanya. Kejujuran, tanggung jawab, adil, empati, dan sifat positif lainnya yang dimiliki oleh seorang guru diharapkan akan berpengaruh dan menjadi teladan yang baik bagi siswa. Dengan ungkapan lain, apabila menghendaki siswa memiliki kecerdasan emosional dan spiritual yang tinggi hal ini harus dimulai dari guru yang juga memiliki kualitas kecerdasan emosional dan spiritual yang tinggi pula.

E. Mulyasa menyatakan kompetensi kepribadian adalah kemampuan kepribadian yang mantap, stabil, dewasa, arif dan berwibawa, menjadi teladan bagi peserta didik, dan berakhlak mulia. ${ }^{26}$

Kompetensi kepribadian guru sebagai bagian dari soft skills memegang peran yang cukup penting untuk mendidik akhlak mulia kepada siswa. Guru dituntut bukan hanya mampu menyajikan metode belajar yang menyenangkan. Lebih dari itu, guru sebagai sosok pendidik juga ditagih kemampuannya memberikan teladan yang baik.

Guru yang memiliki kompetensi kepribadian yang matang mampu mengolah diri secara tepat dan bijaksana. Hal itu ditunjukkan melalui sikap berikut ini:

1. Bertindak berdasarkan norma agama, hukum, sosial dan kebudayaan Indonesia. Hal ini dapat dibuktikan dengan adanya sikap menghargai tanpa membedakan status dan bertindak sesuai norma yang berlaku.

2. Menampilkan diri sebagai pribadi yang mantap, stabil, dewasa, arif dan berwibawa.

3. Menampilkan diri sebagai pribadi yang beriman, islam dan ihsan, berakhlak mulia, bertakwa dan menjadi teladan.

4. Etos kerja dan tanggung jawab tinggi, bangga menjadi seorang guru, percaya diri, mandiri dan profesional.

5. Menjunjung tinggi, memahami, menerapkan dan berperilaku sesuai dengan kode etik guru. ${ }^{27}$

Sosok guru berkepribadian mulia merupakan figur yang ideal bagi pendidikan akhlak siswa. Peran dan fungsi guru tidak bisa digantikan

\footnotetext{
${ }^{26}$ E. Mulyasa, Standar Kompetensi dan Sertifikasi Guru, Bandung, PT Remaja Rosdakarya, 2007, hal. 117.

${ }^{27}$ Ramayulis, Filsafat Pendidikan Islam, Jakarta, Kalam Mulia, 2015, hal. 236
} 
karena ketika proses belajar berlangsung terjalin hubungan sosial antara guru dan siswa. Pada konteks ini perilaku guru yang mencerminkan kepribadian mulia menjadi teladan yang baik (uswah hasanah) bagi siswa.

Dalam tulisannya Hamka menyatakan:

Guru adalah sosok yang digugu dan ditiru. Digugu artinya diindahkan atau dipercayai. Sedangkan ditiru artinya dicontoh atau diikuti. Ditilik dan ditelusuri dari bahasa aslinya, Sansekerta, kata guru adalah gabungan dari kata "gu" dan "ru". Gu artinya kegelapan, kejumudan dan kekelaman. Sedangkan "ru" artinya melepaskan, menyingkirkan, atau membebaskan. ${ }^{28}$

Dari pendapat di atas bisa ditegaskan bahwa tugas dan peran guru adalah membebaskan siswa dari perilaku tercela melalui teladan yang baik. Hal itu dapat terwujud apabila guru memiliki kompetensi kepribadian yang utuh, seimbang dan bijaksana.

Fathiyah Hasan mengutip pendapat Imam Ghazali, "Sekiranya tabiat manusia tidak mungkin dapat diubah, tentu nasihat dan bimbingan tidak ada gunanya. Sekiranya akhlak itu tidak dapat menerima perubahan niscaya fatwa, nasihat dan pendidikan itu adalah hampa. ${ }^{29}$

\section{KESIMPULAN}

Fenomena melorotnya akhlak generasi bangsa tidak cukup diatasi dengan kecaman. Orangtua dan guru memiliki tanggung jawab memelihara perilaku terpuji anak dan siswa melalui praktik pendidikan yang menjadi ladang persemaian agar siswa menjadi manusia yang berakhlak mulia.

Peran dan tugas guru bukan sebatas melakukan transfer ilmu pengetahuan. Dibutuhkan kompetensi kepribadian dan kompetensi sosial sebagai soft competence untuk mendidik akhlak siswa. Hal ini menunjukkan soft skills seorang guru menjadi perangkat lunak yang selalu menyertai proses belajar.

Soft skill memiliki dua dimensi yang terkait dengan kecerdasan seseorang termasuk guru, yaitu keterampilan mengatur dirinya sendiri (intra-personal skills) dan keterampilan berhubungan dengan orang lain (interpersonal skills). Diharapkan guru memiliki kecerdasan emosional dan spiritual yang menjadi fondasi kepribadiannya. Melalui kompetensi kepribadian yang matang dan seimbang guru mampu menjadikan dirinya sebagai teladan yang baik bagi para siswa. Menangani krisis akhlak bisa

\footnotetext{
${ }^{28}$ Hamka Abdul Aziz, Karakter Guru Profesional, (Jakarta: Al-Mawardi Prima, 2012), hal. 19

${ }^{29}$ Fathiyah Hasan Sulaiman (1986), Sistem Pendidikan Versi al-Ghazali, Al-Ma.arif, Bandung, Cet. I, hlm. 66.
} 
dimulai dari peningkatan soft skills guru sebagai profil yang bisa digugu dan ditiru.[]

\section{DAFTAR PUSTAKA}

Ali Mudlofir (2011) Modul Pengembangan Soft Skills Guru PAI, Materi Peningkatan Guru Pendidikan Agama Islam. Direktorat Pendidikan Agama Islam, Kementerian Agama Republik Indonesia, Jakarta.

Ali Mudlofir (2011), Modul Pengembangan Soft Skills Guru PAI, Materi Peningkatan Guru Pendidikan Agama Islam, Direktorat Pendidikan Agama Islam, Kementerian Agama Republik Indonesia.

Bandura A. 1986. Social Foundation of Thought and Action: A Social CognitiveTheory. Englewood Cliffs, New York:Prentice Hall, hal. 361. Available at: http://eprints.undip.ac.id/10382/1/Novikarisma_Wijaya.pdf. Diakses tanggal 14 Pebruari 2013.

Diklat Penjenjangan Auditor Pengendali Teknis (2007), Interpersonal Skill, Pusat Pendidikan dan Pelatihan Pengawasan Badan Pengawasan Keuangan dan Pembangunan, BPKP, Jakarta.

Dr. Abdul Abdul Munip, M.Ag, Reinveting Nilai-Nilai Islam Mengenai Peranan Guru Dalam Pendidikan Karakter, Available at: http://www.scribd.com/doc/12991475/Guru-Dalam-

Pendidikan-Karakter. Diakses 4 November 2011.

E. Mulyasa, Standar Kompetensi dan Sertifikasi Guru, Bandung, PT Remaja Rosdakarya, 2007.

Em Zul Fajri dan Ratu Aprilia Senja, Kamus Lengkeap Babasa Indonesia, Dhifa Publiser, Jakarta, 2003.

Fathiyah Hasan Sulaiman, Sistem Pendidikan Versi al-Ghazali, Bandung, AlMa'arif, Cet. I, 1986.

Hamka Abdul Aziz, Karakter Guru Profesional, Jakarta: Al-Mawardi Prima, 2012.

Lihat Seri Peningkatan Kualitas Pembelajaran TIUI, Keterampilan Mengatur Waktu, Departemen Teknik Industri Universitas Jakarta. Availble at: $\quad$ http://staff.ui.ac.id/internal/132161161/material/Seri4KeterampilanMengelolaWaktu.pdf. Diakses tanggal 13 Pebruari 2013.

Mengenal Hakekat Karakter. Available at: http://charachterbuilding.wordpress.com. Diakses tanggal 14 Pebruari 2013.

Murtadha Muthahhari dan Syekh Tosun Bayrak, Energi Ibadah: Selami Makna, Raih Kematangan Batin, Jakarta, Serambi, 2007. 
Pengembangan Soft Skills dalam Proses Pembelajaran di Perguruan Tinggi, Makna Soft Skills, Jakarta, Direktorat Akademik Direktorat Jenderal Pendidikan Tinggi Departemen Pendidikan Nasional, 2008.

Prof. Dr. H. Sofyan Sauri, M.Pd, Strategi Meningkatkan Pendidikan Akblak Peserta Didik Dalam Proses Pembelajaran, Available at: http://file.upi.edu/Direktori/FPBS/JUR._PEND._BAHASA_A RAB/195604201983011-

SOFYAN_SAURI/makalah2/STRATEGI_MENINGKATKA

N_AKHLAK.pdf. Diakses tanggal 4 November 2011.

Prof. Dr. I Wayan Simri Wicaksana, S.Si., M.Eng, Soft Skills, Gunadarma Univesity. Available at:http://iwayan.info/Lecture/Softskills/MateriKelasSoftSkill_ve r100214_IWS.pdf. Diakses tanggal 13 Pebruari 2013.

Prof. Mohammad Adnan Latief, M.A., Ph.D, Pengembangan Soft Skills Melalui Pembelajaran Bahasa Inggris Berbasis Konteks, Pidato Pengukuhan Guru Besar Dalam Bidang Ilmu Pendidikan Bahasa Inggris Pada Fakultas Sastra Disampaikan pada Sidang Terbuka Senat Universitas Negeri Malang, Departemen Pendidikan Nasional Universitas Negeri Malang, 2007.

Ramayulis, Filsafat Pendidikan Islam, Jakarta, Kalam Mulia, 2015.

Sri Yuliani, Apa Itu Soft Skills. Available at: http:// sriyuliani.staff.fisip.uns.ac.id/kuliah/apa-itu-soft-skills.

Diakses tanggal 13 Pebruari 2013.

Susatyo Yuwono, Mengelola Stres dalam Perspektif Islam dan Psikologi. Available at: jurnal.ump.ac.id/index.php/psikologi/article/download/249/23 5. Diakses tanggal 14 Pebruari 2013.

The Center for Accelerated Learning, What is Accelerated learning. Available at: http://wnw.alcenter.com/what_is.php. Diakses tanggal 14 Pebruari 2013.

Vishal Jain, Importance of Soft Skills Development in Education. Available at: http://schoolofeducators.com/2009/02/importance-of-softskills-development-in-education. Diakses tanggal 13 Pebruari 2013.

Wikipedia, Creativity, Available at: http://en.wikipedia.org/wiki/Creativity. Diakses tanggal 14 Pebruari 2013.

Wikipedia, Soft Skills, Available at: http://en.wikipedia.org/wiki/Soft_skills. Diakses tanggal 4 November 2011. 
William P. Breitsprecher, 2006, Employability Skills. Available at: http://www.breitlinks.com/careers/soft_skills.htm. Diakses tanggal 4 November 2011

Yodhia Antariksa, 4 Pilar Creative Thingking Skills. Available at: http:/ / strategimanajemen.net/2009/12/21/4-pilar-creativethinking-skills. Diakses tanggal 14 Pebruari 2013. 
Ach. Saifullah 